\title{
ANÁLISE ECONÔMICA DA LITIGÂNCIA - PRESSUPOSTOS BÁSICOS E O CÓDIGO DE PROCESSO CIVIL DE 2015 ${ }^{1}$
}

\section{ECONOMIC ANALYSIS OF LITIGATION: BASIC ASSUMPTIONS AND BRAZIL'S 2015 CIVIL PROCEDURE CODE}

Victor Guedes Trigueiro

Advogado da União, Vice-Diretor da Escola da AdvocaciaGeral da União, Doutorando em Direito pelo Centro Universitário de Brasília, Mestre em Direito pela Universidade de Brasília (UnB), Professor da Graduação e Pós-Graduação Lato Sensu do Instituto Brasiliense de Direito Público (IDP), Membro Fundador da Associação Brasiliense de Direito Processual Civil. Brasília/DF. E-mail:vgtrigueiro@gmail.com

João Paulo Resende Borges Analista do Banco Central do Brasil, Pós-graduado em Gestão Governamental e Políticas Públicas pela Universidade Cândido Mendes, Graduado em Relações Internacionais pela Universidade de Brasília (UnB) e em Ciências Econômicas pela UPIS Faculdades Integradas. Discente em Direito no Instituto Brasiliense de Direito Público (IDP). Brasília/DF. Email: johnpaulores@gmail.com.

"I must say that, as a litigant, I should dread a lawsuit beyond almost anything short of sickness and death." Judge Learned Hand. ${ }^{2}$

\footnotetext{
${ }^{1}$ Artigo recebido em 20/05/2019 e aprovado em 29/07/2019.

${ }^{2}$ HAND, Learned, The Deficiencies of Trials to Reach the Heart of the Matter, in: 3 Lectures On Legal Topics, p. 89-105, 1926.
} 
Revista Eletrônica de Direito Processual - REDP.

Rio de Janeiro. Ano 13. Volume 20. Número 2. Maio a Agosto de 2019

Periódico Quadrimestral da Pós-Graduação Stricto Sensu em Direito Processual da UERJ

Patrono: José Carlos Barbosa Moreira (in mem.). ISSN 1982-7636. pp. 313-338

www.redp.uerj.br

RESUMO: Com o objetivo de tornar mais eficiente a litigância no Brasil, aproximando-o a níveis socialmente desejáveis, o Código de Processo Civil de 2015 previu ou aprimorou quatro importantes institutos processuais: conciliação e mediação; sistema de precedentes; multas e honorários sucumbenciais; e atribuição de efeitos vinculantes aos recursos extraordinários com repercussão geral sobrestados. Partindo da base teórica da Análise Econômica da Litigância e por meio de pesquisa aplicada, adotando-se o método hipotéticodedutivo, conclui-se que, ainda que os mencionados institutos não tenham resultado, de imediato, na melhoria dos índices de litigiosidade no país, eles se apresentam como mecanismos de desestímulo à litigância frívola, inclusive aos recursos meramente protelatórios, ao buscar soluções autocompositivas, minimizar o viés do otimismo e reduzir a assimetria de informações.

PALAVRAS-CHAVE: Análise Econômica da Litigância. Código de Processo Civil. Litigância frívola. Autocomposição. Precedentes.

ABSTRACT: In order to turn litigation more efficient in Brazil, by bringing it closer to socially desirable levels, the Civil Procedure Code of 2015 envisaged or improved four important procedural institutes: conciliation and mediation; precedents system; fines and sucumbencial fees; and attribution of binding effects to extraordinary remedies with general repercussions. Based on the theoretical basis of the Economic Analysis of Litigation and through applied research adopting the hypothetical-deductive method, the present study concludes that, although the mentioned institutes have not immediately resulted in quantitative improvement of litigation numbers, they work as mechanisms to discourage frivolous litigation, including remedies to only delay the process, to seek self-solving solutions, to minimize the bias of optimism, and to reduce the information asymmetry.

KEYWORDS: Economic Analysis of Litigation. Civil Procedure Code. Frivolous litigation. Self-composition; Judicial precedents. 


\section{INTRODUÇÃO}

Um dos principais objetivos que ensejaram a elaboração e a promulgação do Código de Processo Civil (CPC), Lei no 13.105 , de 16 de março de 2015, é aproximar o nível de litigância no Brasil a padrões socialmente desejáveis.

Por meio de pesquisa aplicada, descritivo-explicativa, bibliográfica e qualitativa, e adotando o método hipotético-dedutivo, o presente artigo busca investigar se os seguintes institutos processuais do CPC de 2015 têm o condão de contribuir para uma estrutura de litigância eficaz: (i) mecanismos de incentivo à conciliação e mediação; (ii) sistema de precedentes do art. 927, inciso III; e (iii) multas e indenizações por recursos protelatórios nos casos de má-fé, de que trata o art. 81, e a sucumbência recursal elastecida de que trata o art. $85, \S 11$, do CPC.

Nessa perspectiva, são analisados, para o período de março de 2016 a agosto de 2018, os seguintes dados: (i) indicadores de conciliação e mediação consolidados na Justiça Estadual e na Justiça Federal, publicados pelo CNJ, bem como os dados de pesquisa de satisfação de usuário, publicada pelo Tribunal de Justiça do Distrito Federal; (ii) incidentes de resolução de demandas repetitivas publicados pelo TJDFT, (iii) no âmbito do Superior Tribunal de Justiça, incidentes de assunção de competência, recursos especiais repetitivos afetados e transitados em julgado nesse período e acórdãos que façam referência aos arts. 81 e $85, \S 11$, do CPC; e (iv) e a atribuição de efeitos vinculantes aos recursos extraordinários com repercussão geral e sobrestados na forma do art. 1035, § $5^{\circ}$ combinado com o art. 927, inciso III do CPC.

O referencial teórico utilizado é a teoria econômica da litigância, a qual tem por objetivos avaliar os motivos econômicos que podem fazer surgir a litigância e ponderar vantagens e desvantagens econômicas do recurso à litigância judicial ou à resolução de litígios ${ }^{3}$.

É sabido que regras de direito processual podem modificar significativamente o andamento dos processos e os níveis de litigância, bem como alterar variáveis que afetam as

${ }^{3}$ PATRÍCIO, Miguel Carlos Teixeira. Análise económica da litigância. Coimbra: Almedina. Janeiro, 2005. 
Revista Eletrônica de Direito Processual - REDP.

Rio de Janeiro. Ano 13. Volume 20. Número 2. Maio a Agosto de 2019

Periódico Quadrimestral da Pós-Graduação Stricto Sensu em Direito Processual da UERJ

Patrono: José Carlos Barbosa Moreira (in mem.). ISSN 1982-7636. pp. 313-338

www.redp.uerj.br

mais diferentes decisões de agentes envolvidos - inclusive as decisões de iniciar disputa judicial ou de apresentar recurso.

Assim, tendo por base a teoria da análise econômica da litigância (AEL), parte-se do pressuposto de que, ao construírem um quadro de incentivos que induza os agentes a comportamentos eficazes, os institutos acima mencionados têm o condão de reduzir os níveis de litigância no Brasil.

Esse estudo justifica-se pela importância do referencial teórico da Análise Econômica do Direito e de sua aplicação ao importante tema da litigância no Brasil, cujo nível tem se mostrado elevado ao longo dos anos. Além disso, a análise da eficácia do novo CPC no que tange ao seu objetivo de tornar mais eficazes as soluções de conflito no Brasil mostra-se de suma importância.

Nesse sentido, esse artigo está dividido em cinco partes, além desta introdução. $\mathrm{Na}$ segunda parte, é apresentado o referencial teórico do artigo. Na terceira, são discutidos os institutos processuais do CPC de 2015 com potencial de redução dos níveis de litigância no Brasil, já mencionados. A quarta parte traz a análise de dados sobre esses institutos e sobre o nível de litigância no Brasil. Por fim, apresentam-se as considerações finais do texto.

\section{ANÁLISE ECONÔMICA DA LITIGÂNCIA - PRESSUPOSTOS BÁSICOS}

A AED consiste na reformulação da disciplina do Direito em sentido econômico, com o fim de resolver problemas judiciais que se relacionam com a eficiência do Direito em si, com os gastos para efetivação de seus institutos, bem como com os impactos decorrentes de eventuais intervenções judiciais ${ }^{4}$. Um dos campos de aplicação da análise econômica é o direito processual, a que se pode denominar de Análise Econômica da Litigância.

A rigor, entende-se por litígio uma controvérsia ou discussão formada em juízo, ou seja, perante o Poder Judiciário. Nesse aspecto, a visão mais estrita da AEL pode ser entendida como a utilização das ferramentas da AED para o estudo das disputas judiciais, principalmente em relação às ações das partes e os efeitos de certas regras substantivas e

${ }^{4}$ PIMENTA, Eduardo Goulart; LANA, Henrique Avelino. Análise econômica do direito e sua relação com o direito civil brasileiro. Revista Faculdade de Direito UFMG. Belo Horizonte, nº 57, p. 85-138, 2010. 
Revista Eletrônica de Direito Processual - REDP.

Rio de Janeiro. Ano 13. Volume 20. Número 2. Maio a Agosto de 2019

Periódico Quadrimestral da Pós-Graduação Stricto Sensu em Direito Processual da UERJ

Patrono: José Carlos Barbosa Moreira (in mem.). ISSN 1982-7636. pp. 313-338

www.redp.uerj.br

procedimentais em seu comportamento ${ }^{5}$. Essa teoria considera que o objetivo do sistema processual deve ser minimizar os custos dos direitos e das decisões judiciais equivocadas, com base, entre outros critérios, em pressupostos de eficiência ${ }^{6}$.

Contudo, em uma visão mais abrangente e moderna, que adotaremos no presente artigo, a litigância tem um sentido mais amplo que perpassa desde o surgimento do conflito (e a decisão de levar ou não a juízo) até a sua resolução (seja judicial ou por acordo) ${ }^{7}$. Assim, observada a limitação de racionalidade e os limites da análise de custo-benefício, a teoria da AEL assevera que, em termos gerais, o demandante decide processar quando o custo do litígio é menor do que os benefícios esperados, os quais incluem os possíveis resultados de acordos e os possíveis resultados de julgamentos ${ }^{8}$.

Destaca-se que não há correlação positiva entre o incentivo privado para se processar e o nível social ótimo de litigância uma vez que o demandante toma a decisão avaliando apenas os custos próprios, e não os custos do acusado ou do Estado 9 .

Há três principais fontes de divergência entre incentivos privados e sociais de dispêndio com litígios: (i) os gastos privados que não alteram o resultado do julgamento ou dos acordos se constituem um desperdício social; (ii) os gastos privados podem enganar o tribunal ao invés de aumentar a precisão de resultados, o que resulta em valor social negativo; e (iii) mesmo que as despesas melhorem a precisão dos resultados, elas podem não ser socialmente ideais em magnitude ${ }^{10}$.

Sob essa perspectiva, as decisões judiciais podem ser caracterizadas como recurso comum, para as quais o benefício privado tende, com alta probabilidade, a ser superior ao custo privado. Em decorrência, a estratégia dominante é a divergência, de forma que há um forte incentivo às partes agirem como litigantes, o que se denomina tragédia dos comuns ${ }^{11}$.

\footnotetext{
${ }^{5}$ KOBAIASHI, Bruce H; PARKER, Jeffrey S. Civil procedure: general economic analysis. In> BOUCKAERT, Boudewijn; DE GEEST, Gerrit (Eds). Encyclopedia of law and economics. Cheltenham: Edward Elgar, 2000, v. 1.

${ }^{6}$ POSNER, Richard A. A economia da justiça. Tradução Evandro Ferreira e Silva, revisão da tradução Anibal Mari - São Paulo: Editora WMF Martins Fontes, 2010.

${ }^{7}$ SILVA, De Plácido e. Vocabulário jurídico. 17ed. Rio de Janeiro: Forense, 2000.

${ }^{8}$ KAPLOW, Louis; SHAVELL, Steven. Economic Analysis of Law. Harvard Law School. Handbook of Public Economics, Volume 3, Edited by A.J Auerbach and M. Feldstein. Elsevier Science B. V, 2002.

${ }^{9}$ PATRÍCIO, Miguel Carlos Teixeira. Análise económica da litigância. Coimbra: Almedina, Janeiro, 2005. ${ }^{10}$ SHAVELL, Steven. The Level of Litigation: Private Versus Social Optimality of Suit and of Settlement. International Review of Law and Economics, v. 19, p. 99-115, 1999.

${ }^{11}$ GICO JR, Ivo Teixeira. A tragédia do Judiciário. RDA - Revista de Direito Administrativo, Rio de Janeiro, v. 267, p. 163-198, set./dez. 2014.
} 
Revista Eletrônica de Direito Processual - REDP.

Rio de Janeiro. Ano 13. Volume 20. Número 2. Maio a Agosto de 2019

Periódico Quadrimestral da Pós-Graduação Stricto Sensu em Direito Processual da UERJ

Patrono: José Carlos Barbosa Moreira (in mem.). ISSN 1982-7636. pp. 313-338

www.redp.uerj.br

Grande parte das demandas que ingressam no Poder Judiciário são demandas

frívolas, assim consideradas aquelas de baixa probabilidade de êxito e para as quais o valor dos benefícios que o demandante pode obter é bem inferior aos custos ${ }^{12 \mathrm{e} 13}$. No Brasil, o grande número de processos indica o mesmo comportamento por parte dos litigantes.

Em alguns casos, os autores frívolos, ao ingressarem com ações, buscam apenas obter um acordo favorável, ainda que reconheçam a falta de mérito do processo. Tratam-se de situações de oportunismo em que se busca pagamentos às expensas de réus inocentes que podem ser vistos como defraudados ou sob coação ${ }^{14}$.

Essas situações de oportunismo são mais frequentes em mercados não regulados e com alta oferta de advogados, que apresentem concorrência por preço ou qualidade, ou ambos ${ }^{15}$. Além disso, a ausência de barreiras formais para a apresentação de uma ação judicial também aumenta a proporção frívola de ações. Não obstante, há uma série de casos de litigância frívola em que os autores de fato creem que as ações podem prosperar e que têm razão de mérito ${ }^{16}$.

Essas demandas são recorrentes em casos de assimetria de informação. Nessas situações, os demandantes pouco propensos a levar os casos para o Judiciário não conseguem identificar o comportamento dos réus e imitam o comportamento de litigantes contumazes, de forma que se contentam com a possibilidade de um montante positivo.

Outra hipótese de litigância frívola não oportunista são os casos em que, apesar da simetria informativa, o demandante pode iniciar um processo a baixo custo e conta com a possibilidade de que o réu não se comprometerá com um esforço de litígio substancial e de que os tribunais não exerçam grande controle sobre a qualidade dos danos ${ }^{17}$.

A litigância frívola é tanto maior quanto menor a previsibilidade de erros judiciais. Se os erros forem imprevisíveis pelas partes, os processos frívolos só tendem a aumentar, dado que o risco é baixo e o ganho é alto ${ }^{18}$. A principal forma de minimizar o problema do

\footnotetext{
${ }^{12}$ PATRÍCIO, Miguel Carlos Teixeira. Análise económica da litigância. Coimbra: Almedina, Janeiro, 2005. ${ }^{13}$ KAPLOW, Louis; SHAVELL, Steven. Economic Analysis of Law. Harvard Law School. Handbook of Public Economics, Volume 3, Edited by A.J Auerbach and M. Feldstein. Elsevier Science B. V, 2002.

${ }^{14}$ KATZ, Avery. The effect of frivolous lawsuits on the settlement of litigation. International Review of Law and Economics, v. 10, p. 3-27, 1990.

${ }^{15}$ PATRÍCIO, Miguel Carlos Teixeira. Análise económica da litigância. Coimbra: Almedina, Janeiro, 2005.

${ }^{16}$ KATZ, Avery. The effect of frivolous lawsuits on the settlement of litigation. International Review of Law and Economics, v. 10, p. 3-27, 1990.

${ }^{17}$ KAPLOW, Louis; SHAVELL, Steven. Economic Analysis of Law. Harvard Law School. Handbook of Public Economics, Volume 3, Edited by A.J Auerbach and M. Feldstein. Elsevier Science B. V, 2002.

${ }^{18}$ PATRÍCIO, Miguel Carlos Teixeira. Análise económica da litigância. Coimbra: Almedina, Janeiro, 2005.
} 
Revista Eletrônica de Direito Processual - REDP.

Rio de Janeiro. Ano 13. Volume 20. Número 2. Maio a Agosto de 2019

Periódico Quadrimestral da Pós-Graduação Stricto Sensu em Direito Processual da UERJ

Patrono: José Carlos Barbosa Moreira (in mem.). ISSN 1982-7636. pp. 313-338

www.redp.uerj.br

erro judicial é tornar o sistema legal menos complexo. Aqui se insere o importante papel do sistema de precedentes.

Quanto maior complexidade, extensão ou proliferação de Leis, maior a possibilidade de surgirem ou aumentarem fenômenos de rent seeking ${ }^{19}$. O maior detalhe de regras ex post ou ex ante poupa as partes de custos de transação que resultam da necessidade de aditar, eliminar ou clarificar aspectos da relação contratual ${ }^{20}$

As regras ex ante são entendidas como a legislação positivada. A formulação de regras ex ante menos complexa é mais eficaz nas situações em que o comportamento regulado é frequente e tem características comuns, principalmente em razão de economias de escala .

Não obstante, para comportamentos pouco frequentes e heterogêneos, deixar a especificação de detalhes até o estágio de adjudicação pode economizar a despesa do Estado, porque muitas situações para as quais os detalhes podem ter sido fornecidos nunca surgirão. Nesses casos, a emissão de precedentes pelos tribunais (formulação de regras ex post) tende a ser mais eficaz, uma vez que permitem maior detalhamento, bem como a adoção de técnicas de interpretação mais favoráveis a situações heterogêneas ${ }^{21}$.

Quanto mais as instâncias inferiores forem bem informadas sobre os precedentes dos tribunais superiores, mais elas podem despender recursos no exame de questões fáticas, inclusive ampliando-o, uma vez que o nível de informações é maior. Entretanto, instâncias inferiores mal informadas sobre os precedentes tendem a se dedicar mais a questões de direito, apenas tomando como dadas as evidências factuais apresentadas ${ }^{22}$.

Contudo, o mero desejo de fixação de precedentes não é suficiente para limitar a litigância. É preciso que os sistemas jurídicos contem com regras processuais eficientes, que afetem os interesses dos agentes em litigar ${ }^{23}$. Ao incentivarem ou desincentivarem a

\footnotetext{
${ }^{19}$ Refere-se ao o uso de recursos com o propósito de obter ganhos para as pessoas, onde esses ganhos vêm de alguma atividade com valor social negativo. Nas atividades de rent seeking alguém investe recursos financeiros para conseguir para si uma transferência de renda, em prejuízo do restante da sociedade. Essas vantagens podem tomar diversas formas, como a concessão de benefícios ficais, monopólios privados, restrições de concorrência, pagamento de subsídios, dentre outros. TULLOCK, Gordon; SELDON, Arthur; BRADY, Gordon L. Government failure: a primer in public choice. Washington, D.C.: Cato Institute, 2002. 193p.

${ }^{20}$ PATRÍCIO, Miguel Carlos Teixeira. Análise económica da litigância. Coimbra: Almedina. Janeiro, 2005.

${ }^{21}$ KAPLOW, Louis; SHAVELL, Steven. Economic Analysis of Law. Harvard Law School. Handbook of Public Economics, Volume 3, Edited by A.J Auerbach and M. Feldstein. Elsevier Science B. V, 2002.

${ }^{22}$ DAUGHETY, Andrew, F; REINGANUM, Jennifer, F. Appealing judgment. RAND Journal of Economics Vol. 31, No. 3, Autumn. 2000.

${ }^{23}$ GICO JR, Ivo Teixeira. A tragédia do Judiciário. RDA - Revista de Direito Administrativo, Rio de Janeiro, v. 267, p. 163-198, set./dez. 2014.
} 
Revista Eletrônica de Direito Processual - REDP.

Rio de Janeiro. Ano 13. Volume 20. Número 2. Maio a Agosto de 2019

Periódico Quadrimestral da Pós-Graduação Stricto Sensu em Direito Processual da UERJ

Patrono: José Carlos Barbosa Moreira (in mem.). ISSN 1982-7636. pp. 313-338

www.redp.uerj.br

litigância, os arranjos processuais afetam a alocação dos custos sociais e privados e a eficiência do sistema judicial ${ }^{24}$.

Uma importante regra processual é a previsão de multa e a indenização em razão de recursos protelatórios e a majoração dos honorários sucumbenciais. Quanto maiores as punições pela litigância de má-fé, menor tende a ser o nível de litigância em um sistema judicial.

Outro efeito dessas medidas é a redução do viés de otimismo. Trata-se de um padrão de julgamento que sistematicamente se afasta da prescrição de uma regra normativa. No processo civil, esses vieses existem quando as expectativas dos demandantes sobre o valor dos resultados dos julgamentos são sistematicamente maiores do que as expectativas dos réus.

Destaca-se, ainda, que a presença de vieses cognitivos impede a resolução de disputas, mesmo quando há importantes incentivos para a celebração de acordos. Nessas hipóteses, a simples previsão de regra que exige a adoção de métodos alternativos de solução de conflitos, sem buscar minimizar os vieses cognitivos, geram apenas o efeito de aumentar o custo do litígio ${ }^{25}$.

\section{INSTITUTOS PROCESSUAIS DO CPC DE 2015 COM POTENCIAL DE REDUÇÃO DOS NÍVEIS DE LITIGÂNCIA NO BRASIL}

\subsection{A mediação e a conciliação}

De acordo com o CPC, a realização da audiência de conciliação e mediação é a regra. Conforme dispõe o $\S 4^{\circ}$ do art. 334, a audiência somente não ocorrerá (i) se ambas as partes manifestarem, expressamente, desinteresse na composição consensual ou (ii) quando não se admitir a autocomposição.

O pressuposto da obrigatoriedade da audiência é de que as soluções autocompositivas ex ante (conciliação e mediação) diminuem os custos da resolução das

\footnotetext{
${ }^{24}$ ARENHART, Fernando Santos. A análise econômica da litigância: teoria e evidências. Porto Alegre, 2009.

${ }^{25}$ BABCOCK, Linda; LOEWENSTEIN, George; ISSACHAROFF, Samuel. Creating Convergence: Debiasing Biased Litigants. HeinOnline -- 22 Law \& Soc. Inquiry 9131997.
} 
Revista Eletrônica de Direito Processual - REDP.

Rio de Janeiro. Ano 13. Volume 20. Número 2. Maio a Agosto de 2019

Periódico Quadrimestral da Pós-Graduação Stricto Sensu em Direito Processual da UERJ

Patrono: José Carlos Barbosa Moreira (in mem.). ISSN 1982-7636. pp. 313-338

www.redp.uerj.br

disputas e geram menores riscos e maior probabilidade dos resultados pretendidos ${ }^{26}$. Em outras palavras, as partes reconhecem que a alternativa do acordo é menos custosa e menos arriscada.

Não por outro motivo, o legislador preferiu apostar na possibilidade de a conciliação ou de a mediação vencer a resistência ao acordo em audiência, ainda que tal fato gere uma delonga maior no processo (caso a conciliação ou mediação não restem exitosas) e acabe ofertando à parte ré possibilidade de tempo alargado para preparação de sua defesa ${ }^{27}$.

Ao Judiciário interessa incentivar esses métodos autocompositivos uma vez que se tratam de meios ágeis, informais, céleres, sigilosos, econômicos e eficazes ${ }^{28}$, com potencial para a solução para a crise do Judiciário ${ }^{29}$.

Além disso, as soluções conciliatórias tendem a propiciar uma efetiva solução do conflito, o que se coaduna com o pressuposto de que a autonomia do direito processual não pode desconsiderar o real objetivo do processo, que é a efetivação do direito material ${ }^{30}$. Os métodos autocompositivos são um reforço à participação da população no exercício do poder, na solução dos litígios ${ }^{31}$.

Nesse sentido, a realização da justiça faz-se mais com a celebração de acordos livres do que com o recurso indefinido a instâncias jurisdicionais. Deve-se destacar, porém, que há um importante variável que influencia o êxito de um acordo, qual seja: a limitação de acesso dos litigantes às informações sobre decisão de juízes para casos semelhantes e sobre o comportamento estratégico do outro litigante ${ }^{32}$. Em relação ao primeiro aspecto, o sistema de precedentes do CPC visa dotar as partes de mais informações, de modo a desencorajar litigâncias em desconformidade com a jurisprudência.

\footnotetext{
${ }^{26}$ KAPLOW, Louis; SHAVELL, Steven. Economic Analysis of Law. Harvard Law School. Handbook of Public Economics, Volume 3, Edited by A.J Auerbach and M. Feldstein. Elsevier Science B. V, 2002.

${ }^{27}$ WELSCH, Gisele Mazzoni. Audiência de mediação e conciliação - Art. 334 do CPC/15. Migalhas. Disponível em: <http://www.migalhas.com.br/EntendendoDireito/110,MI246940,101048audiencia+de+mediacao+e+conciliacao+Art+334+do+CPC15> Acesso em outubro de 2018.

${ }^{28}$ CAETANO, Luiz Antunes. Arbitragem e mediação. Rudimentos. São Paulo: Atlas, 2002.

${ }^{29}$ TRENTIN, Taise Rabelo Dutra; TRENTIN, Sandro Seixas. Mediação como um meio alternativo de tratamento de conflitos prevista no novo CPC e na Resolução 125 CNJ. In: Âmbito Jurídico, Rio Grande, XIV, $\quad$ n. $95, \quad$ dez 2011. Disponível em: juridico.com.br/site/?artigo_id=10863\&n_link=revista_artigos_leitura>. Acesso em outubro de 2018.

${ }^{30}$ FRANCO, Cíntia. A solução consensual de conflitos no novo Código de Processo Civil. Direitonet. Março de 2015. Disponível em: <https://www.direitonet.com.br/artigos/exibir/9012/A-solucao-consensual-deconflitos-no-novo-Codigo-de-Processo-Civil>.

${ }^{31}$ DIDIER JUNIOR, Fredie. Curso de Direito Processual Civil - v. 1: Introdução ao Direito Processual Civil, Parte Geral e Processo de Conhecimento. 17. ed. Salvador: JusPODIVM, 2015.

${ }^{32}$ PATRÍCIO, Miguel Carlos Teixeira. Análise económica da litigância. Coimbra: Almedina. Janeiro, 2005.
} 
Revista Eletrônica de Direito Processual - REDP.

Rio de Janeiro. Ano 13. Volume 20. Número 2. Maio a Agosto de 2019

Periódico Quadrimestral da Pós-Graduação Stricto Sensu em Direito Processual da UERJ

Patrono: José Carlos Barbosa Moreira (in mem.). ISSN 1982-7636. pp. 313-338

www.redp.uerj.br

Acerca do segundo ponto, muitas vezes, as partes conhecem as vantagens do acordo, mas não o realizam devido ao desconhecimento sobre estratégias das outras partes. Em decorrência disso, há sistemas processuais, como o norteamericano, que preveem a partilha obrigatória de informações, mediante a revelação prévia das provas a serem produzidas em juízo ${ }^{33}$. No Brasil, porém, não há mecanismos obrigatórios de revelação de informações. Nessa situação, a simples previsão de audiência obrigatória de conciliação e mediação, por si só, não torna mais eficaz os níveis de litigância no País. Os acordos tenderão a ocorrer na hipótese de os custos do uso dos mecanismos de partilha voluntária sejam inferiores aos custos de levar a lide a julgamento ${ }^{34}$.

A instituição de centros judiciais de conciliação e mediação, a formação de profissionais nessa área e a criação de ambiente de empatia tendem a reduzir os custos dos mecanismos de partilha voluntária. Entretanto, mesmo nesses casos, as partes podem não entrar em acordo devido à existência de vieses cognitivos, em especial o viés de otimismo. Nessas hipóteses, a simples introdução de regras legais que busquem reduzir os níveis de litigância sem considerar aspectos de economia comportamental tendem a ser pouco eficazes. Assim, a regra que exige a adoção de métodos alternativos de solução de conflitos, sem buscar minimizar os vieses cognitivos, pode gerar apenas o efeito de aumentar o custo do litígio ${ }^{35}$.

\subsection{O Sistema de Precedentes}

As regras normativas são, por definição, genéricas e abstratas, não cabendo a elas prever os problemas e as situações concretas, que demandam interpretação dos juízes.

Não obstante, decisões judiciais variantes acabam incentivando a litigiosidade dos agentes, uma vez que dificultam o cálculo dos riscos baseados em probabilidade e tendo em

\footnotetext{
${ }^{33}$ KAPLOW, Louis; SHAVELL, Steven. Economic Analysis of Law. Harvard Law School. Handbook of Public Economics, Volume 3, Edited by A.J Auerbach and M. Feldstein. Elsevier Science B. V, 2002. ${ }^{34}$ FARMER, Amy; PECORINO, Paul. Civil Litigation with Mandatory Discovery and Voluntary Transmission of Private Information. Working Paper No. 03-08-01. The University of Alabama, 2003. ${ }^{35}$ BABCOCK, Linda; LOEWENSTEIN, George; ISSACHAROFF, Samuel. Creating Convergence: Debiasing Biased Litigants. HeinOnline -- 22 Law \& Soc. Inquiry 9131997.
} 
Revista Eletrônica de Direito Processual - REDP.

Rio de Janeiro. Ano 13. Volume 20. Número 2. Maio a Agosto de 2019

Periódico Quadrimestral da Pós-Graduação Stricto Sensu em Direito Processual da UERJ

Patrono: José Carlos Barbosa Moreira (in mem.). ISSN 1982-7636. pp. 313-338

www.redp.uerj.br

vista a limitação cognitiva do viés de otimismo ${ }^{36}$. Essas situações geram o aumento das demandas frívolas, oportunistas ou não.

No primeiro caso, a falta de uniformização de entendimentos gera em agentes oportunistas maior expectativa de que a outra parte aceite acordos em razão do menor grau de certeza de êxito ou de que, mesmo não havendo acordo, possam ser exitosos na demanda oportunista uma vez que os juízes podem interpretar os casos de forma diversa.

No caso de agentes não oportunistas, uma vez que a assimetria de informações é maior em casos de decisões judiciais variantes, a litigância frívola tende a aumentar nos casos em que não se aplique o sistema de precedentes.

Assim, cabe à jurisprudência o esforço de uniformização de entendimentos com o objetivo de conferir maior segurança jurídica aos agentes. O ponto é que esse nível de segurança depende do arcabouço de regras processuais que induzam os agentes a um comportamento eficaz.

Nessa perspectiva, o art. 927, inciso III, do CPC cria ou amplia importantes institutos processuais voltados a garantir vinculatividade aos sistemas de precedentes, fornecendo um sistema coerente e estável de incentivos que induzam a um comportamento eficiente. São previstos dois novos incidentes processuais, Incidente de Resolução de Demandas Repetitivas (IRDR) e Incidente de Assunção de Competência (IAC) e são ampliados os efeitos e a vinculatividade dos recursos repetitivos, inclusive com sua admissão para os casos de recursos extraordinários.

Em termos gerais, esses institutos de precedentes permitem maior detalhamento do que as regras normativas, bem como a adoção de técnicas de interpretação mais favoráveis a situações heterogêneas, atuando como formulação de regras ex post, que, quanto mais claras, mais desincentivam a litigância.

Além disso, quanto mais bem informados os juízes e as Cortes de $2^{\circ}$ grau sobre os precedentes, mais eles tendem a se dedicar ao exame e à gestão das provas, dado que as questões de direito já estarão esclarecidas, o que reduz a probabilidade de recursos, reduzindo o nível de litigância.

\footnotetext{
${ }^{36} \mathrm{GICO}$ JR, Ivo Teixeira. A tragédia do Judiciário. RDA - Revista de Direito Administrativo, Rio de Janeiro, v. 267, p. 163-198, set./dez. 2014.
} 
Revista Eletrônica de Direito Processual - REDP.

Rio de Janeiro. Ano 13. Volume 20. Número 2. Maio a Agosto de 2019

Periódico Quadrimestral da Pós-Graduação Stricto Sensu em Direito Processual da UERJ

Patrono: José Carlos Barbosa Moreira (in mem.). ISSN 1982-7636. pp. 313-338

www.redp.uerj.br

A aplicação reiterada dos precedentes, o que se pode denominar de investimento

em capital jurídico, permite que os agentes realizem previsões sobre como o magistrado se comportará nesses casos, o que pode viabilizar a reversão da tendência de sobreutilização do Judiciário ${ }^{37}$.

O CPC inovou ao prever o IRDR e aprimorar o IAC. Ambos incidentes processuais veiculam a discussão de questões de direito que se repetem em vários processos ou que tenham grande repercussão social, cuja decisão se torna obrigatória, devendo ser reproduzida em todos os demais casos que discutem o mesmo tema.

O IRDR é incidente que busca viabilizar uma verdadeira concentração de processos que versem sobre uma mesma questão de direito no âmbito dos tribunais de $2^{\circ}$ grau, permitindo que a decisão a ser proferida vincule todos os demais casos sob sua competência territorial, promovendo melhorias na tutela de direitos difusos, coletivos e individuais homogêneos.

O IAC consiste no deslocamento da competência funcional de órgão fracionário que seria originariamente competente para apreciar o recurso, o processo de competência originária ou a remessa necessária, para um órgão colegiado de maior composição do mesmo Tribunal ${ }^{38}$.

São requisitos para a instauração do IAC: (i) questão de direito; (ii) grande repercussão geral; (iii) não repetição em múltiplos processos; e (iv) existência de interesse público $^{39}$.

No que tange aos recursos repetitivos, enquanto no CPC de 1973 eles estavam previstos apenas para o recurso especial, na sistemática do CPC de 2015 eles estão previstos também para os recursos extraordinários.

Além disso, o Código vigente amplia os efeitos e a vinculatividade de um recurso repetitivo ao prever que, quando houver a afetação de um recurso repetitivo, o ministro

\footnotetext{
${ }^{37}$ GICO JR, Ivo Teixeira. A tragédia do Judiciário. RDA - Revista de Direito Administrativo, Rio de Janeiro, v. 267, p. 163-198, set./dez. 2014.

${ }^{38}$ MIRANDA, Maylton Rodrigues. Incidente de assunção de competência: instrumento para a justiça das decisões judiciais. Publicado em 6 de julho de 2016. Disponível em: <http://www.conteudojuridico.com.br/artigo,incidente-de-assuncao-de-competencia-instrumento-para-ajustica-das-decisoes-judiciais,56209.html>. Acesso em outubro de 2018.

${ }^{39}$ BECKER, Rodrigo; TRIGUEIRO, Victor. O novo incidente de assunção de competência e o STJ. Jota. Publicado em 15 de dezembro de 2016. Disponível em: <https://www.jota.info/opiniao-eanalise/colunas/coluna-cpc-nos-tribunais/o-novo-incidente-de-assuncao-de-competencia-e-o-stj-15122016>. Acesso em outubro de 2018.
} 
Revista Eletrônica de Direito Processual - REDP.

Rio de Janeiro. Ano 13. Volume 20. Número 2. Maio a Agosto de 2019

Periódico Quadrimestral da Pós-Graduação Stricto Sensu em Direito Processual da UERJ

Patrono: José Carlos Barbosa Moreira (in mem.). ISSN 1982-7636. pp. 313-338

www.redp.uerj.br

relator determinará a suspensão do processamento de todos os processos pendentes, individuais ou coletivos, que versem sobre a questão e tramitem no território nacional.

Também é vinculante a decisão em sede de repetitivos dado que, caso o tribunal de origem mantenha o acórdão divergente, o recurso especial ou extraordinário será remetido ao respectivo tribunal superior.

Em termos gerais, o CPC de 2015 imprime maior racionalidade ao julgamento de recursos que envolvem questões de massa, respeitando o princípio da isonomia e o mínimo de praticidade e eficiência, que devem caracterizar a atividade do Judiciário.

Ainda, cabe destacar o instituto da repercussão geral, o qual exige que a questão constitucional trazida nos recursos extraordinários possua repercussão geral para que seja analisada pelo Supremo Tribunal Federal.

Em caráter de inovação da ordem jurídica, o CPC de 2015 estabeleceu regra que possibilitou a suspensão da tramitação de processos, individuais ou coletivos, na esfera nacional, quando reconhecida a repercussão geral de determinado tema constitucional, pela Suprema Corte. É o que dispõe o artigo $1.035, \S 5^{\circ}$, do novo código ${ }^{40}$. Alia-se a isso os efeitos vinculantes conferidos aos recursos extraordinários, conforme dispõe o art. 927, inciso III, do CPC.

Nesse sentido, ao julgar um recurso extraordinário com a repercussão geral e dada a suspensão nos demais processos idênticos, a decisão pelo STF sobre a matéria impacta nos demais processos sobrestados existentes no próprio tribunal ou, ainda, represados nos tribunais anteriores, de forma que uma única decisão do STF passa a ser multiplicada em todo o Brasil. São consideráveis, portanto, os ganhos de eficiência.

Ao definir a questão constitucional pela repercussão geral, numa análise mista entre caso concreto e aplicabilidade em abstrato, o STF consegue um rumo material de decisão para aplicabilidade múltipla dessa decisão, aplicando nos processos sobrestados, desafogando da análise pormenorizada dos tribunais, existente ou não uma multiplicidade de processos ${ }^{41}$.

\footnotetext{
${ }^{40}$ BECKER, Rodrigo; TRIGUEIRO, Victor. O novo incidente de assunção de competência e o STJ. Jota. Publicado em 15 de dezembro de 2016. Disponível em: <https://www.jota.info/opiniao-eanalise/colunas/coluna-cpc-nos-tribunais/o-novo-incidente-de-assuncao-de-competencia-e-o-stj-15122016>. Acesso em outubro de 2018.

${ }^{41}$ LEMOS, Vinícius Silva. A repercussão geral no novo CPC: a construção da vinculação da decisão de mérito proferida em repercussão geral pelo STF. Revista Eletrônica de Direito Processual - REDP, volume 18, n. $1,2017$.
} 
Revista Eletrônica de Direito Processual - REDP.

Rio de Janeiro. Ano 13. Volume 20. Número 2. Maio a Agosto de 2019

Periódico Quadrimestral da Pós-Graduação Stricto Sensu em Direito Processual da UERJ

Patrono: José Carlos Barbosa Moreira (in mem.). ISSN 1982-7636. pp. 313-338

www.redp.uerj.br

3.3. A multa e a indenização em razão de recursos protelatórios e a majoração dos honorários sucumbenciais.

O CPC de 1973 já disciplinava a litigância de má-fé com o objetivo de inibi-la. Entretanto, apesar de frequente, o valor da multa sob a vigência do antigo Código era irrisório e, na prática, ela não tinha o efeito inibitório desejado. Por sua vez, a indenização era rara.

O CPC de 2015 torna mais gravosa a multa, que deve ser superior a $1 \%$ e inferior a $10 \%$ do valor corrigido da causa. Ademais, estabelece que, quando o valor da causa for irrisório ou inestimável, a multa poderá ser fixada em até dez vezes o valor do saláriomínimo, o que busca inibir prática recorrente no passado que consistia em fixar valores baixos de causa para que, no caso de fixação de multa, os montantes a serem pagos fossem insignificantes. No caso da indenização, além de não haver mais o limitador de $20 \%$, a base de cálculo não é mais o valor da causa.

Destaca-se, ainda, que o diploma legal fixou parâmetros objetivos para incidência da multa e da indenização, os quais incidem não apenas sobre o valor da condenação, mas também sobre o proveito econômico obtido ou, não sendo possível mensurá-los, sobre o valor atualizado da causa. No CPC de 1973, os parâmetros objetivos aplicavam-se apenas sobre o valor da condenação, devendo ser aplicada a regra equitativa nos demais $\operatorname{casos}^{42}$.

Por oportuno, convém esclarecer que, nos termos do art. $90, \S 4^{\circ}$ do CPC, se o réu reconhecer a procedência do pedido e, simultaneamente, cumprir integralmente a prestação reconhecida, os honorários sucumbenciais serão reduzidos pela metade. Essa regra reduz os custos da litigância, inclusive para o Estado.

$\mathrm{O} \S 1^{\circ}$ do art. 85 prevê a regra da cumulatividade dos honorários fixados em matéria de reconvenção, de cumprimento de sentença, provisório ou definitivo, e de recursos. Isso significa que, à verba honorária estabelecida por ocasião do julgamento da demanda inicial devem ser somados honorários próprios pelo trabalho desempenhado pelo advogado na

\footnotetext{
${ }^{42}$ TUCCI, José Rogério Cruz. Novo Código de Processo Civil traz mudanças nos honorários advocatícios. Agosto de 2015. Disponível em: <https://www.conjur.com.br/2015-ago-18/paradoxo-corte-cpc-trazmudancas-honorarios-advocaticios>. Acesso em outubro de 2018.
} 
Revista Eletrônica de Direito Processual - REDP.

Rio de Janeiro. Ano 13. Volume 20. Número 2. Maio a Agosto de 2019

Periódico Quadrimestral da Pós-Graduação Stricto Sensu em Direito Processual da UERJ

Patrono: José Carlos Barbosa Moreira (in mem.). ISSN 1982-7636. pp. 313-338

www.redp.uerj.br

demanda reconvencional, na execução provisória ou definitiva do julgado e na instância recursal, desde que o total não ultrapasse o percentual de $20 \%$.

Importa destacar que esse limite alcança, inclusive, a regra do art. $85, \S 11$, que, estabelece o dever do Tribunal de majorar os honorários advocatícios quando do julgamento de um recurso, levando em conta o trabalho adicional. Nesses termos, toda vez que não conhecer ou negar provimento a um recurso interposto contra decisão que tenha deliberado sobre honorários advocatícios e houver trabalho adicional ulteriormente realizado pelo advogado do recorrido, o tribunal deve majorar a verba honorária anteriormente fixada, na medida de tal trabalho, respeitando-se o teto legal para a fase de conhecimento de $20 \%{ }^{43}$.

Esse conjunto de medidas tem por premissa aumentar o custo do litígio, o que tende a tornar mais desfavorável ao demandante a equação que o compara com os benefícios esperados.

O resultado tende a ser a redução do nível de litigância geral, mas principalmente, o nível de litigância frívola ${ }^{44}$, mesmo no caso de agentes oportunistas que somente buscam um acordo favorável, uma vez que, na não ocorrência do acordo, os custos da sucumbência seriam maiores.

Além disso, o aumento de custos tende a minimizar o problema do viés de otimismo, de forma a aproximar os custos privados dos custos sociais da litigância, reduzindo o problema da litigância como recurso comum, inclusive por meio do incentivo, ainda que indireto, a ações autocompositivas.

\section{ANÁLISE DE DADOS SOBRE OS INSTITUTOS PROCESSUAIS DO CPC DE 2015 E SOBRE O NÍVEL DE LITIGÂNCIA NO BRASIL}

Os dados apresentados nessa seção se referem ao período de março de 2016 a agosto de 2018.

\footnotetext{
${ }^{43}$ É importante observar, porém, que o percentual de $20 \%$ não impede a cobrança de adicional na fase de cumprimento de sentença. Nesse contexto, não é impossível que o valor total dos honorários advocatícios sucumbenciais estabelecidos no processo chegue a até $40 \%$ do valor da disputa: $20 \%$ na fase de conhecimento e $20 \%$ na fase de cumprimento de sentença.

${ }^{44}$ No caso de litigantes frívolos que creem que as ações podem prosperar e que têm razão de mérito, os efeitos do aumento dos custos da litigância tendem a ser menores do que no caso de litigantes sabidamente frívolos. Ainda assim, o aumento de custos desencoraja as demandas.
} 
Revista Eletrônica de Direito Processual - REDP.

Rio de Janeiro. Ano 13. Volume 20. Número 2. Maio a Agosto de 2019

Periódico Quadrimestral da Pós-Graduação Stricto Sensu em Direito Processual da UERJ

Patrono: José Carlos Barbosa Moreira (in mem.). ISSN 1982-7636. pp. 313-338 www.redp.uerj.br

As tabelas a seguir mostram os dados relativos a processos não criminais, na fase de conhecimento, no $1^{\circ}$ grau e no Juizado Especial, respectivamente na Justiça Estadual e na Justiça Federal, para os anos de 2015 e 2016. O intuito é aferir minimamente o impacto do CPC no processo civil nas instâncias inferiores.

A análise se concentrará especialmente no $1^{\circ}$ grau, uma vez que o CPC aplica-se apenas subsidiariamente aos Juizados Especiais. Apesar disso, alguns dados desses juizados são exibidos para fins de comparabilidade. Os dados foram extraídos do Relatório Justiça em Números de $2017^{45}$.

Tabela 1: Dados da Justiça Estadual relativos a processos não criminais $-1^{\circ}$ grau e JEC

\begin{tabular}{|c|c|c|c|}
\hline Indicador & 2015 & 2016 & $\begin{array}{c}\text { Variação } \\
\text { Percentual }\end{array}$ \\
\hline Casos Novos $\left(1^{\circ}\right.$ Grau e JE) & 9.720 .567 & 9.757 .001 & $0,37 \%$ \\
\hline Sentença por caso novo ( $1^{\circ}$ grau e JE) & $1,03 \%$ & $1,26 \%$ & $22,33 \%$ \\
\hline Taxa de congestionamento ( $1^{\circ}$ grau e JE) & $66,15 \%$ & $66 \%$ & $-0,27 \%$ \\
\hline Índice de Conciliação ( $\left.1^{\circ} \mathrm{Grau}\right)$ & $10,77 \%$ & $12,5 \%$ & $16,06 \%$ \\
\hline Índice de conciliação (JE) & $19,29 \%$ & $18,7 \%$ & $-3,06 \%$ \\
\hline $\begin{array}{c}\text { Sentenças homologatórias de acordo } 1^{\circ} \\
\text { grau }\end{array}$ & 76.972 & 126.889 & $64,85 \%$ \\
\hline Sentenças homologatórias de acordo JE & 52.286 & 79.553 & $52,15 \%$ \\
\hline $\begin{array}{l}\text { Recorribilidade interna Fase de } \\
\text { Conhecimento }\left(1^{\circ} \text { grau }\right)\end{array}$ & $4,67 \%$ & $3,70 \%$ & $-20,77 \%$ \\
\hline $\begin{array}{l}\text { Recorribilidade interna Fase de } \\
\text { Conhecimento (JE) }\end{array}$ & $3,22 \%$ & $3,56 \%$ & $10,56 \%$ \\
\hline
\end{tabular}

Fonte: Justiça em números, 2017.

\footnotetext{
${ }^{45}$ BRASIL. Justiça em Números 2017: ano-base 2016/Conselho Nacional de Justiça - Brasília: CNJ, 2017.
} 
Revista Eletrônica de Direito Processual - REDP.

Rio de Janeiro. Ano 13. Volume 20. Número 2. Maio a Agosto de 2019

Periódico Quadrimestral da Pós-Graduação Stricto Sensu em Direito Processual da UERJ

Patrono: José Carlos Barbosa Moreira (in mem.). ISSN 1982-7636. pp. 313-338

www.redp.uerj.br

Tabela 2: Dados da Justiça Federal relativos a processos não criminais - $1^{\circ}$ grau e JEC

\begin{tabular}{|c|c|c|c|}
\hline Indicador & 2015 & 2016 & $\begin{array}{c}\text { Variação } \\
\text { Percentual }\end{array}$ \\
\hline Casos Novos $\left(1^{\circ}\right.$ Grau e JE $\left.)\right)$ & 1.743 .330 & 1.790 .319 & $2,7 \%$ \\
\hline Sentença por caso novo $\left(1^{\circ}\right.$ grau e JE) & $0,89 \%$ & $0,89 \%$ & - \\
\hline $\begin{array}{l}\text { Taxa de congestionamento }\left(1^{\circ} \text { grau e }\right. \\
\mathrm{JE})\end{array}$ & $61,59 \%$ & $61,78 \%$ & - \\
\hline Índice de Conciliação $\left(1^{\circ} \mathrm{Grau}\right)$ & $2,55 \%$ & $4,67 \%$ & $83,13 \%$ \\
\hline Índice de conciliação (JE) & $5,89 \%$ & $5,84 \%$ & $0,84 \%$ \\
\hline $\begin{array}{c}\text { Sentenças homologatórias de acordo } 1^{\circ} \\
\text { grau }\end{array}$ & 8.135 & 13.730 & $68,77 \%$ \\
\hline $\begin{array}{l}\text { Sentenças homologatórias de acordo } \\
\text { JE }\end{array}$ & 197.661 & 145.963 & $26,15 \%$ \\
\hline $\begin{array}{l}\text { Recorribilidade interna Fase de } \\
\text { Conhecimento }\left(1^{\circ} \text { grau }\right)\end{array}$ & $12,2 \%$ & $14,12 \%$ & $15,73 \%$ \\
\hline $\begin{array}{l}\text { Recorribilidade interna Fase de } \\
\text { Conhecimento (JE) }\end{array}$ & $2,69 \%$ & $2,59 \%$ & $-3,71 \%$ \\
\hline
\end{tabular}

Fonte: Justiça em números, 2017.

Na Justiça Estadual, o índice de conciliação no $1^{\circ}$ grau sofreu relevante acréscimo, enquanto caiu no caso do JEC. Além disso, a recorribilidade interna caiu no primeiro caso e aumentou no segundo. As sentenças homologatórias de acordos aumentaram significativamente nos dois casos.

Na Justiça Federal, o índice de conciliação sofreu relevante acréscimo no $1^{\circ}$ grau enquanto praticamente não se alterou no JEC. As sentenças homologatórias aumentaram de forma relevante principalmente no primeiro caso. Apesar disso, houve aumento da recorribilidade interna no primeiro caso e queda no segundo. 
Revista Eletrônica de Direito Processual - REDP.

Rio de Janeiro. Ano 13. Volume 20. Número 2. Maio a Agosto de 2019

Periódico Quadrimestral da Pós-Graduação Stricto Sensu em Direito Processual da UERJ

Patrono: José Carlos Barbosa Moreira (in mem.). ISSN 1982-7636. pp. 313-338

www.redp.uerj.br

Em termos gerais, ainda que essas medidas tenham sido insuficientes para afetar significativamente a taxa de congestionamento dos Tribunais, os dados das tabelas acima demostram que, de certo modo, houve avanços no que se refere a medidas autocompositivas no $1^{\circ}$ grau, após a entrada em vigor do CPC. O índice de conciliação e as sentenças homologatórias de acordo tiveram aumento relativo expressivo entre os dois anos.

Em comparação com os Juizados Especiais, nos quais já havia previsão legal de audiências autocompositivas, verificamos que a adoção das medidas de conciliação e mediação no $1^{\circ}$ grau da justiça ordinária teve efeitos significativos em termos relativos. Ainda que não se possa atribuir exclusivamente ao CPC a causa para os melhores resultados entre 2015 e 2016, a lógica econômica por trás das mencionadas medidas nos permite inferir que houve um incentivo ao comportamento do acordo, frente a anterior falta de incentivo a métodos alternativos de solução de conflitos.

Em termos de satisfação dos participantes de medidas autocompositivas, cabe destacar alguns dados relativos à Pesquisa de Satisfação do Usuário dos serviços de conciliação e mediação do Núcleo Permanente de Mediação e Conciliação do TJDFT ${ }^{46}$.

De acordo com o relatório de 2017 desse Núcleo, 38\% dos usuários dos serviços ficaram muito satisfeitos com a atuação do $\mathrm{Núcleo}^{47}$, 53\% ficaram satisfeitos e apenas $10 \%$ ficaram insatisfeitos ou muito insatisfeitos.

Além disso, 86,4\% dos usuários se sentiram pelo menos parcialmente responsáveis pela resolução do conflito e mais de $88 \%$ dos usuários consideraram a tentativa de acordo válida ou parcialmente válida. Ainda, para $85 \%$ dos advogados, os acordos obtidos nas sessões de mediação gerariam economia processual de 1 a 2 anos a seus clientes. Ademais, a economia processual com os acordos era, em média, de $\mathrm{R} \$ 500,00$ a 1.000,00 para 30,1\%, de $\mathrm{R} \$ 2.000,00$ a 4.000,00 para 33,3\% e de $\mathrm{R} \$ 5.000,00$ a 7.000,00, para 11,9\% deles.

Em relação ao sistema de precedentes do CPC, especificamente sobre o IRDR, observamos que, no âmbito do TJDFT foram admitidos 11 desses incidentes, sendo que desses apenas 05 resultaram na publicação de acórdãos.

\footnotetext{
${ }^{46}$ BRASIL. Relatório anual NUPEMEC. Tribunal de Justiça do Distrito Federal e Territórios. 2017.

${ }^{47}$ Os usuários são convidados a responder, voluntariamente, questões que versem sobre o alcance das expectativas, o nível de satisfação, a atuação dos conciliadores, mediadores e prepostos, a visão acerca do Poder Judiciário e a percepção geral sobre a negociação. São avaliados aspectos como a validade da tentativa de acordo, a sensação de justiça com o resultado da negociação, a existência ou não de pressão para fechamento de acordo e outros aspectos gerais da prestação de serviço
} 
Revista Eletrônica de Direito Processual - REDP.

Rio de Janeiro. Ano 13. Volume 20. Número 2. Maio a Agosto de 2019

Periódico Quadrimestral da Pós-Graduação Stricto Sensu em Direito Processual da UERJ

Patrono: José Carlos Barbosa Moreira (in mem.). ISSN 1982-7636. pp. 313-338

www.redp.uerj.br

Entre os publicados, o incidente com maior número de ações sobrestadas foi o IRDR $01^{48}$, número do incidente $2016002013471-4$, com 13.841 sobrestamentos, que trata da definição da natureza jurídica do encargo de $10 \%$ (dez por cento) do valor do crédito tributário inscrito em dívida ativa. Nos demais casos, o número de sobrestamentos foi bem inferior (284, no IRDR 3; 46, no IRDR 7; 26, no IRDR 6; e zero, no IRDR 9).

No que tange ao outro incidente, o IAC, há apenas quatro no âmbito do STJ. Três deles ainda não foram julgados. $\mathrm{O}$ único ${ }^{49}$ submetido a julgamento foi admitido em fevereiro de 2017 e julgado em junho de 2018. O total de processos suspensos neste caso foram de 113 e a questão submetida a julgamento foi o cabimento de prescrição intercorrente e eventual imprescindibilidade de intimação prévia do credor, bem como a necessidade de oportunidade para o autor dar andamento ao processo paralisado por prazo superior àquele previsto para a prescrição da pretensão veiculada na demanda.

Em relação aos recursos repetitivos, entre a data de entrada em vigor do CPC até julho de 2018, foram afetados 30 recursos repetitivos, totalizando 134.303 processos sobrestados. Desses, apenas 10 transitaram em julgado, totalizando 20.201 processos afetados.

No que tange aos recursos extraordinários recebidos com repercussão geral, importantes decisões foram tomadas do STF a partir de 2016, de forma que processos que estavam sobrestados, na forma requerida pelo art. 1.035, $\S 5^{\circ}$, do CPC, passaram a ter suas teses jurídicas fixadas. Em outras palavras, as questões jurídicas de vários processos foram definidas com base em poucas, porém, importantes, decisões da Suprema Corte, o que se alinha à literatura econômica.

\footnotetext{
${ }^{48} \mathrm{~A}$ tese fixada foi a seguinte: $\mathrm{O}$ encargo de $10 \%$ do valor do crédito inscrito em dívida ativa, previsto no art. 42 , $\S \S 1^{\circ}$ e $2^{\circ}$ da Lei Complementar n. ${ }^{\circ} 4 / 94$, não perde a natureza de encargo pelo fato de, após arrecadado pelo titular (ente público), ser destinado aos advogados públicos do Distrito Federal. O encargo do art. 42 da CTDF, executado em conjunto com o crédito tributário pelo rito das execuções fiscais, nos termos do art. 39, $\S 4^{\circ}$ da Lei $4.320 / 64$ e do art. $2^{\circ}, \S \S 1^{\circ}$ e $2^{\circ}$ da LEF, ainda que não tenha natureza tributária é receita pública que Pode ser inscrita em dívida ativa. A Vara de Execuções Fiscais do DF é competente para execução da totalidade do encargo de $10 \%$ previsto no art. $42, \S 2^{\circ}$, do CTDF.

${ }^{49} \mathrm{~A}$ tese firmada foi a seguinte: 1.1 . Incide a prescrição intercorrente, nas causas regidas pelo $\mathrm{CPC} / 73$, quando o exequente permanece inerte por prazo superior ao de prescrição do direito material vindicado, conforme interpretação extraída do art. 202, parágrafo único, do Código Civil de 2002. 1.2. O termo inicial do prazo prescricional, na vigência do CPC/1973, conta-se do fim do prazo judicial de suspensão do processo ou, inexistindo prazo fixado, do transcurso de 1 (um) ano (aplicação analógica do art. 40, § $2^{\circ}$, da Lei 6.830/1980). 1.3. O termo inicial do art. 1.056 do $\mathrm{CPC} / 2015$ tem incidência apenas nas hipóteses em que o processo se encontrava suspenso na data da entrada em vigor da novel lei processual, uma vez que não se pode extrair interpretação que viabilize o reinício ou a reabertura de prazo prescricional ocorridos na vigência do revogado CPC/1973 (aplicação irretroativa da norma processual).
} 
Revista Eletrônica de Direito Processual - REDP.

Rio de Janeiro. Ano 13. Volume 20. Número 2. Maio a Agosto de 2019

Periódico Quadrimestral da Pós-Graduação Stricto Sensu em Direito Processual da UERJ

Patrono: José Carlos Barbosa Moreira (in mem.). ISSN 1982-7636. pp. 313-338

www.redp.uerj.br

Entre esses casos, destacam-se os seguintes temas: (i) incidência de juros de mora no período compreendido entre a data da conta de liquidação e a expedição do requisitório (25.286 processos sobrestados); (ii) concessão de benefício especial a estrangeiros residentes no país (428 processos sobrestados); (iii) responsabilidade subsidiária da Administração Pública por encargos trabalhistas gerados pelo inadimplemento de empresas prestadoras de serviços (71.524 processos sobrestados); (iv) incidência do teto remuneratório a servidores já ocupantes de dois cargos públicos antes da vigência da Emenda Constitucional nº 41/2003 (45 processos sobrestados); (v) pagamento imediato de reparação econômica a anistiados políticos (285 processos sobrestados); (vi) limites subjetivos de coisa julgada referente à ação coletiva proposta por entidade associativa de caráter civil (3.936 processos sobrestados); (vii) validade da correção monetária e dos juros moratórios incidentes sobre as condenações impostas à Fazenda Pública, conforme previsto na Lei nº 9.494/1997(107.256 processos sobrestados); (viii) submissão dos conselhos de fiscalização profissional à execução pelo regime de precatórios (17 processos sobrestados); e (ix) prescritibilidade da prestação de ressarcimento ao erário em face de agentes públicos por ato de improbidade administrativa (1.018 processos sobrestados).

Cabe destacar, porém, que, ainda que muitos dos casos julgados com base no instituto da repercussão geral sejam de extrema relevância, verifica-se que, em termos quantitativos, o percentual de processos julgados com base nesse instituto não gera impactos nominais significativos frente a grande quantidade de processos que aguardam julgamento pela Suprema Corte.

O mesmo raciocínio quantitativo se aplica aos institutos do IRDR, do IAC e dos repetitivos. $\mathrm{Na}$ realidade, os dados indicam que, em termos numéricos, o sistema de precedentes não parece ter sido adotado em toda a sua potencialidade pelos Tribunais, de forma que o número de institutos instaurados ainda não é amplo o suficiente que nos permita inferir sobre a razoabilidade econômica deles.

Apesar disso, ainda que o impacto nominal global não seja significativo, muitos dos temas discutidos tratam de importantes questões, como as acima mencionadas relativas a recursos extraordinários, afetando, de uma só vez, processos que seriam julgados individualmente.

Além disso, parte dos efeitos do sistema de precedentes deve ser aferida ao longo do tempo pelo número de potenciais litigantes que deixam de ingressar com ação uma vez 
Revista Eletrônica de Direito Processual - REDP.

Rio de Janeiro. Ano 13. Volume 20. Número 2. Maio a Agosto de 2019

Periódico Quadrimestral da Pós-Graduação Stricto Sensu em Direito Processual da UERJ

Patrono: José Carlos Barbosa Moreira (in mem.). ISSN 1982-7636. pp. 313-338

www.redp.uerj.br

que a tese firmada lhe é contrária ou pela celeridade dos julgamentos de casos relacionados a essa tese. Em adição, o caráter recente desses institutos não nos permite tirar conclusões precipitadas.

No que tange à multa em razão de recursos protelatórios, no âmbito do STJ, 25 acórdãos mencionavam o art. 81 do CPC. Desses, 13 previam a imposição de multas protelatórias. Em média, a multa foi de apenas 2,81\%, mas em dois casos houve a imposição de multa em salário mínimo, tendo em vista o valor baixo das causas.

Nos demais 12 casos o STJ não aplicou multa, seja porque entendia que não era caso de má-fé, seja porque aplicou o entendimento da Súmula 7 indicando que a aplicação da multa exigia o exame de fatos, seja porque entendeu ser cabível ao caso apenas a imposição de advertência de que novo recurso seria considerado protelatório.

Cabe destacar que, em nenhum dos 25 casos analisados, houve a imposição de indenização por litigância de má-fé.

Sobre a majoração dos honorários sucumbenciais, o STJ emitiu o Enunciado Administrativo $\mathrm{n}^{\mathrm{o}} 7^{50}$. Com base nele, o Tribunal vem proferindo decisões no sentido de não admitir a alteração de honorários advocatícios para adequá-los à regra prevista no prevista no artigo $85, \S 11$, do CPC, quando o acórdão contra o qual foi interposto o recurso especial foi publicado na vigência do CPC antigo.

Além disso, apesar da obviedade, não custa mencionar que a majoração pressupõe a existência de imposição de verba honorária pelas instâncias ordinárias, revelando-se vedada aquela quando esta não houver sido imposta.

Ademais, o STJ tem afirmado que, uma vez que a fixação de honorários recursais em favor do patrono da parte recorrida tem o nítido propósito de desestimular a interposição de recurso infundado pela parte vencida, a fixação de honorários recursais está adstrita às hipóteses de não conhecimento ou improvimento do recurso (AgInt nos EREsp 1.539.725/DF, Rel. Ministro ANTONIO CARLOS FERREIRA, julgado em 09/08/2017, DJe de 19/10/2017).

Além disso, deve-se mencionar que o Enunciado no 16 da Escola Nacional de Formação e Aperfeiçoamento de Magistrados dispõe sobre a impossibilidade de majoração

\footnotetext{
${ }^{50}$ Somente nos recursos interpostos contra decisão publicada a partir de 18 de março de 2016, será possível o arbitramento de honorários sucumbenciais recursais, na forma do art. 85, § 11, do CPC.
} 
Revista Eletrônica de Direito Processual - REDP.

Rio de Janeiro. Ano 13. Volume 20. Número 2. Maio a Agosto de 2019

Periódico Quadrimestral da Pós-Graduação Stricto Sensu em Direito Processual da UERJ

Patrono: José Carlos Barbosa Moreira (in mem.). ISSN 1982-7636. pp. 313-338

www.redp.uerj.br

de honorários na hipótese de interposição de recurso no mesmo grau de jurisdição (art. 85, $\S 11$, do CPC/2015).

Assim, em termos gerais, a majoração incide apenas quando esta Corte julga, pela vez primeira, o recurso, sujeito ao CPC de 2015, que inaugure o grau recursal, de forma que o Tribunal tem entendido que é indevida sua fixação em agravo interno e embargos de declaração (AgInt no REsp 1568139 / SP. DJe 23/05/2018).

O entendimento, portanto, é de que a majoração é cabível apenas nos casos de recursos que, de fato, inaugurem grau recursal.

Nesses casos de recursos que inaugurem grau recursal e observados os três requisitos mencionados, o exame da jurisprudência do STJ para o período de março de 2016 a julho de 2108 demonstra que esse Tribunal vem aplicando a majoração dos honorários recursais.

Além disso, a Corte vem firmando o entendimento de que não se exige comprovação de trabalho adicional do advogado no grau recursal, tratando-se apenas de critério de quantificação da verba (AgInt nos EDcl no REsp 1357561/MG, Rel. Ministro MARCO AURÉLIO BELLIZZE, Terceira Turma, DJe 19/04/2017).

\section{CONSIDERAÇÕES FINAIS}

Os indicadores de conciliação e mediação após a entrada em vigor do CPC de 2015 demonstram predisposição das partes em aderir aos métodos alternativos de solução de conflitos, que além de serem mais ágeis, informais, céleres, permitem, de fato, a efetivação do direito material das partes.

Apesar disso, a previsão de mecanismos de conciliação e mediação, por si só, não garante a redução da assimetria informativa entre os agentes e nem afeta os custos de levar a lide a julgamento.

Uma vez que a decisão dos agentes de litigar é baseada no cálculo dos custos vis a vis os benefícios esperados com o processo, o sistema de precedentes tende a tornar mais claro aos agentes os benefícios esperados com o processo, enquanto as multas e a majoração dos honorários recursais aumentam os custos da litigância em geral, especialmente a frívola.

No caso dos precedentes, ainda que não se possa considerar irrelevante o número de processos afetados em IRDR, IAC, repetitivos e recursos extraordinários recebidos com 
Revista Eletrônica de Direito Processual - REDP.

Rio de Janeiro. Ano 13. Volume 20. Número 2. Maio a Agosto de 2019

Periódico Quadrimestral da Pós-Graduação Stricto Sensu em Direito Processual da UERJ

Patrono: José Carlos Barbosa Moreira (in mem.). ISSN 1982-7636. pp. 313-338

www.redp.uerj.br

repercussão geral a proporção destes frente ao total de processos nos Tribunais não é suficiente para concluirmos que esse sistema aumente a eficiência do Poder Judiciário.

Apesar disso, para além da questão quantitativa, o esforço de uniformização de precedentes não pode ser desconsiderado. Alguns dos casos permitiram a fixação de importantes teses jurídicas, em especial os recursos extraordinários tratados neste artigo. Nesses casos, a litigância frívola tende a estar afastada, uma vez que a interpretação é muito clara, havendo pouca margem para acordos que beneficiem apenas o litigante frívolo ou de decisões judiciais variantes.

Nesses termos, o sistema de precedentes inaugurado ou aperfeiçoado pelo CPC de 2015, se não permitiu redução significativa de processos, ao menos imprimiu racionalidade econômica ao processo. Na prática, porém, o que se observa é que os resultados não são melhores mais em razão da atuação tímida dos Tribunais.

Essa mesma questão acima se aplica ao caso das multas. O objetivo claro desse instituto é de desincentivar a litigância de má-fé (ações frívolas ou recursos meramente protelatórios) por meio do aumento do custo do litígio. Entretanto, também aqui se verifica uma atuação tímida do STJ. Em muitos casos, esse Tribunal não vem aplicando a multa ou a aplica em percentual irrisório. Por sua vez, a indenização praticamente não é aplicada.

Situação distinta é a da majoração dos honorários sucumbenciais. O exame da jurisprudência do STJ demonstra que essa Corte vem aplicando esse instituto nos casos de decisões publicadas após a entrada em vigor do CPC de 2015.

Com base no exposto, entende-se que o Código previu medidas alinhadas à teoria da análise econômica da litigância, com o intuito de tornar mais eficiente o nível de litigância no Brasil.

Em termos gerais, ainda que a simples instauração dos institutos analisados não tenha resultado, de imediato, na melhoria dos índices de litigiosidade no Brasil, é possível inferir que os institutos analisados apresentam-se como mecanismos de desincentivo à litigância frívola e aos recursos protelatórios e à busca por soluções autocompositivas de conflitos, além de permitir a minimização do viés de otimismo.

O principal fator limitante a que esses institutos produzam resultados mais relevantes é a efetiva adoção destes pelos Tribunais como forma de incentivo a comportamentos de litigância eficaz. 


\section{REFERÊNCIAS}

ARENHART, Fernando Santos. A análise econômica da litigância: teoria e evidências. Porto Alegre, 2009.

BRASIL. Justiça em Números 2017: ano-base 2016/Conselho Nacional de Justiça Brasília: CNJ, 2017.

BRASIL. Relatório anual NUPEMEC. Tribunal de Justiça do Distrito Federal e Territórios. 2017.

BABCOCK, Linda; LOEWENSTEIN, George; ISSACHAROFF, Samuel. Creating Convergence: Debiasing Biased Litigants. HeinOnline -- 22 Law \& Soc. Inquiry 913 1997.

BECKER, Rodrigo; TRIGUEIRO, Victor. O novo incidente de assunção de competência e o STJ. Jota. Publicado em 15 de dezembro de 2016. Disponível em: <https://www.jota.info/opiniao-e-analise/colunas/coluna-cpc-nos-tribunais/o-novoincidente-de-assuncao-de-competencia-e-o-stj-15122016>. Acesso em outubro de 2018.

BECKER, Rodrigo; TRIGUEIRO, Victor. Repercussão Geral e suspensão da tramitação de processos. Jota. Publicado em 12 de janeiro de 2017. Disponível em: https://www.jota.info/opiniao-e-analise/colunas/coluna-cpc-nostribunais/repercussao-geral-e-suspensao-da-tramitacao-de-processos-12012017

CAETANO, Luiz Antunes. Arbitragem e mediação. Rudimentos. São Paulo: Atlas, 2002.

DAUGHETY, Andrew, F; REINGANUM, Jennifer, F. Appealing judgment. RAND Journal of Economics, Vol. 31, No. 3, Autumn. 2000

DIDIER JUNIOR, Fredie. Curso de direito processual civil - v. 1: introdução ao direito processual civil, parte geral e processo de conhecimento. 17. ed. Salvador: JusPODIVM, 2015.

FARMER, Amy; PECORINO, Paul. Civil Litigation with Mandatory Discovery and Voluntary Transmission of Private Information. Working Paper No. 03-08-01. The University of Alabama, 2003.

FRANCO, Cíntia. A solução consensual de conflitos no novo Código de Processo Civil. Direitonet. Março de $2015 . \quad$ Disponível em: 
Revista Eletrônica de Direito Processual - REDP.

Rio de Janeiro. Ano 13. Volume 20. Número 2. Maio a Agosto de 2019

Periódico Quadrimestral da Pós-Graduação Stricto Sensu em Direito Processual da UERJ

Patrono: José Carlos Barbosa Moreira (in mem.). ISSN 1982-7636. pp. 313-338 www.redp.uerj.br

<https://www.direitonet.com.br/artigos/exibir/9012/A-solucao-consensual-deconflitos-no-novo-Codigo-de-Processo-Civil>.

GICO JR, Ivo Teixeira. A tragédia do Judiciário. RDA - Revista de Direito Administrativo, Rio de Janeiro, v. 267, p. 163-198, set./dez. 2014.

KAPLOW, Louis; SHAVELL, Steven. Economic Analysis of Law. Harvard Law School.

Handbook of Public Economics, Volume 3, Edited by A.J Auerbach and M. Feldstein. Elsevier Science B. V, 2002.

KATZ, Avery. The effect of frivolous lawsuits on the settlement of litigation. International Review of Law and Economics (1990), 10(3-27).

KOBAIASHI, Bruce H; PARKER, Jeffrey S. Civil procedure: general economic analysis. In> BOUCKAERT, Boudewijn; DE GEEST, Gerrit (Eds). Encyclopedia of law and economics. Cheltenham: Edward Elgar, 2000, v. 1.

LEMOS, Vinícius Silva. A repercussão geral no novo CPC: a construção da vinculação da decisão de mérito proferida em repercussão geral pelo STF. Revista eletrônica de direito processual - REDP, volume 18, n. 1, 2017.

MIRANDA, Maylton Rodrigues. Incidente de assunção de competência: instrumento para a justiça das decisões judiciais. Publicado em 6 de julho de 2016. Disponível em: $\quad<$ http://www.conteudojuridico.com.br/artigo,incidente-de-assuncao-decompetencia-instrumento-para-a-justica-das-decisoes-judiciais,56209.html>. Acesso em outubro de 2018.

PATRÍCIO, Miguel Carlos Teixeira. Análise económica da litigância. Almedina, Coimbra, Janeiro, 2005.

PIMENTA, Eduardo Goulart; LANA, Henrique Avelino. Análise econômica do direito e sua relação com o direito civil brasileiro. Revista Faculdade de Direito UFMG. Belo Horizonte, $\mathrm{n}^{\mathrm{o}} 57$, p. 85-138, 2010.

POSNER, Richard A. A economia da justiça. Tradução Evandro Ferreira e Silva, revisão da tradução Anibal Mari - São Paulo: Editora WMF Martins Fontes, 2010.

ROSEMBERG, David; STEVEN Shavell. A Model in Which Suits Are Brought for Their Nuisance Value. International Review of Law and Economics, 5, 3-13, 1985. In: KATZ, Avery. The effect of frivolous lawsuits on the settlement of litigation. International Review of Law and Economics (1990), 10(3-27). 
Revista Eletrônica de Direito Processual - REDP.

Rio de Janeiro. Ano 13. Volume 20. Número 2. Maio a Agosto de 2019

Periódico Quadrimestral da Pós-Graduação Stricto Sensu em Direito Processual da UERJ

Patrono: José Carlos Barbosa Moreira (in mem.). ISSN 1982-7636. pp. 313-338 www.redp.uerj.br

SHAVELL, Steven. The Level of Litigation: Private Versus Social Optimality of Suit and of Settlement. International Review of Law and Economics 19:99 -115, 1999.

SILVA, De Plácido e. Vocabulário jurídico. 17 ed. Rio de Janeiro: Forense, 2000.

TRENTIN, Taise Rabelo Dutra; TRENTIN, Sandro Seixas. Mediação como um meio alternativo de tratamento de conflitos prevista no novo CPC e na Resolução 125

CNJ. In: Âmbito Jurídico, Rio Grande, XIV, n. 95, dez 2011. Disponível em: $<$ http://ambito-

juridico.com.br/site/?artigo_id=10863\&n_link=revista_artigos_leitura>. Acesso em outubro de 2018.

TUCCI, José Rogério Cruz. Novo Código de Processo Civil traz mudanças nos honorários advocatícios. Agosto de 2015. Disponível em: <https://www.conjur.com.br/2015-ago-18/paradoxo-corte-cpc-traz-mudancashonorarios-advocaticios>. Acesso em outubro de 2018.

TULLOCK, Gordon; SELDON, Arthur; BRADY, Gordon L. Government failure: a primer in public choice. Washington, D.C.: Cato Institute, 2002. 193p

WELSCH, Gisele Mazzoni. Audiência de mediação e conciliação - Art. 334 do CPC/15. Migalhas. Disponível em:

<http://www.migalhas.com.br/EntendendoDireito/110,MI246940,101048audiencia + de + mediacao+e+conciliacao+Art+334+do+CPC15> Acesso em outubro de 2018. 